\title{
ecancermedicalscience \\ Psychological impact of fertility preservation techniques in women with gynaecological cancer
}

\author{
Antonio Simone Laganà ${ }^{1}$, Valentina Lucia La Rosa ${ }^{2}$, Agnese Maria Chiara Rapisarda $^{3}$, Alessio Platania ${ }^{4}$ and Salvatore Giovanni Vitale ${ }^{1}$ \\ 'Unit of Gynaecology and Obstetrics, Department of Human Pathology in Adulthood and Childhood "G Barresi”, University of Messina, Messina, 98125, Italy \\ 2Unit of Psychodiagnostics and Clinical Psychology, University of Catania, Catania, 95124, Italy \\ ${ }^{3}$ Department of General Surgery and Medical Surgical Specialties, University of Catania, Catania, 95124, Italy \\ ${ }^{4}$ Department of Health Services and Epidemiological Observatory, Palermo, 90121, Italy \\ Correspondence to: Valentina Lucia La Rosa. E-mail: psicolarosa@gmail.com
}

\begin{abstract}
Gynaecological cancer is a very stressful experience for women and treatments can compromise fertility and reproductive capacity. Fertility preservation techniques in women with gynaecological cancer can play an important role in improving the quality of life of these patients but, in many cases, the information about this type of treatment is not adequate. It is important to further investigate this topic in order to reduce the impact of gynaecological cancer on the quality of life of survivors as much as possible.
\end{abstract}

Keywords: female, fertility preservation, reproduction, quality of life

ecancer 2017, 11:ed62 DOI: 10.3332/ecancer.2017.ed62

Copyright: (c) the authors; licensee ecancermedicalscience. This is an Open Access article distributed under the terms of the Creative Commons Attribution License (http://creativecommons.org/licenses/by/3.0), which permits unrestricted use, distribution, and reproduction in any medium, provided the original work is properly cited. 
Gynaecological cancer affects around $17 \%$ of women worldwide [1]. The most common types are endometrial cancer followed by ovarian, cervical, and vulvar cancer [1, 2], although other rare malignancies may occur [3]. Endometrial cancer is the most common gynaecological malignancy in Western countries [4]. Surgery is the primary treatment for most patients while adjuvant radiation therapy or chemotherapy is recommended in more advanced stages of disease [5-7]. Ovarian cancer is the most lethal form of gynaecological cancer and it is generally diagnosed in an advanced stage [1]. Treatment consists of a combination of extensive surgery and chemotherapy, and it is often associated with high incidence of adverse events [8-10] and recurrence [11, 12]. Cervical cancer is often diagnosed during the reproductive years [1]. Treatment may consist of a combination of surgery and radiation therapy [13]. Vulvar cancer accounts for 3-5\% of all gynaecological cancers [1]. It usually occurs in older women but it can also appear in younger women [1]. Treatment is surgical with or without adjuvant radiotherapy [14].

The diagnosis of a gynaecological cancer is a very stressful experience for women with a significant impact on their psychological, sexual and social functioning $[1,2,15,16]$. Women with gynaecological cancer suffer from depression, anxiety, suicidal ideation, feelings of anger and shame, lower self-esteem and a poor quality of life (QoL) [1, 2, 15-19]. Moreover, treatments for gynaecological cancer often lead to physical and sexual changes that impair female identity and sexual functioning $[1,2,15,16]$. Thanks to the most recent advances in cancer therapy, the number of long-term gynaecological cancer survivors has increased and a primary objective with these patients is to improve their quality of life and psychological well-being. Gynaecological cancer often affects women in childbearing age and treatments can compromise fertility and reproductive capacity. Young women with a gynaecological cancer often experience psychological distress with the loss of menstrual function and the loss of fertility. In particular, psychological distress related to infertility is more significant in women who have not yet started their families and would still like to do so [20-22].

A cancer survivor may assign a high value to parenthood because a child is a symbol of life that defeats death and the opportunity for women to give birth to something beautiful [23-26]. Consequently, fertility preservation techniques in women with gynaecological cancer can play an important role in improving quality of life of these patients. Despite the fact that gynaecological cancers often require radical surgery which deprives the patient of her fertility, the development of fertility-sparing surgery (FSS) has radically changed the scenario of fertility preservation: regarding cervical cancer, radical trachelectomy with lymph node assessment became the standard of care for selected women with lesions $<2 \mathrm{~cm}$ who desire fertility preservation [27]; in addition, for patients ineligible for FSS or who require adjuvant radiation therapy, current options include ovarian transposition and cryopreservation of oocytes or embryos [28]. Regarding endometrial cancer, new evidence regarding the possibility of fertility-sparing treatment in young patients with early stage (IA, G1 and 2) endometrioid endometrial cancer treated by combined hysteroscopic resection and progestin therapy changed the perspective of the disease [29].

A recent systematic review suggests also that FSS is feasible and safe in early-stage epithelial ovarian cancer (stage IA and IC grade 1 and 2 disease and stage IC1 according to the new FIGO staging system) [30]. In all the cases in which it is not possible to perform fertilitysparing treatments, radical surgery treatment (hysterectomy, bilateral ovariectomy) deprives patients of the possibility to have offspring. In addition, (neo)adjuvant treatments (radio and/or chemotherapy) may also play a detrimental role on fertility and must be tailored to the patient's individual characteristics [31]. The most effective fertility preservation strategy is embryo cryopreservation which requires in vitro fertilization and a male partner [32]. Oocyte banking and $\mathrm{GnRH}$ analog treatment are more problematic and do not preserve fertility in all patients. Currently, cryopreservation of ovarian tissue appears to be a very promising fertility preservation technique. It is an easy, fast and less expensive technique that has excellent prospects of fertility preservation [32, 33].

Physicians don't always discuss fertility preservation with cancer patients of childbearing age and this may be due to their insufficient knowledge regarding these techniques and lack of specific communication strategies [21,34]. Many factors may interfere with the communication between patient and physician concerning fertility preservation: physician knowledge of fertility preservation techniques and their efficacy, distress and anxiety of the patient, and financial problems may adversely affect decision-making process about fertility preservation [35]. This process is complex and many factors can come into play. For example, cognitive aspects, such as biases and heuristics, may make decision-making about fertility preservation more difficult and less aware [36]. In these cases, decision support interventions or decision aids are appropriate to facilitate and support the decision-making process, reducing the possible biases [36]. Decision aids increase knowledge and reduce decisional conflict without increasing anxiety. They provide information about cancer and female fertility, and discuss the different available fertility options and the advantages and disadvantages of each one [37]. Also the P5 approach may be very useful to improve decision-making about fertility preservation and to transform patients into active decision-makers in the treatment process [38].

(Cont.) 
Therefore it is important to provide complete information about fertility-preservation options, in order to take into account the patient's individual background and to consider the patient's emotional and psychological needs. Adequate counseling about fertility preservation techniques improves the quality of life of women who survive after gynaecological cancer [39, 40]. A multidisciplinary approach is important and psychologists should be involved in a team approach to cancer care. Indeed, reproductive counseling aims not only to choose the most appropriate fertility preservation technique according to the prognosis and the risk of infertility related to cancer treatments, but also to assess the real desire of woman to become mothers. Moreover, considering the impact of gynaecological cancer on the psychological well-being of women affected and the complexity of the decisions surrounding fertility preservation, psychosocial counseling may be useful to discuss the psychological problems and stressors associated with cancer and fertility preservation [41-43].

\section{Conclusions}

Despite the importance of this topic, studies on the psychological and emotive effects of fertility preservation techniques are still scarce. For this reason, we strongly suggest the further investigation of this topic in order to reduce as much as possible the impact of gynaecological cancer on the quality of life of survivors.

\section{Conflicts of interest}

The authors declare that they have no conflict of interest.

\section{Authors' contributions}

Antonio Simone Laganà conceived the manuscript; Valentina Lucia La Rosa wrote the manuscript; Agnese Maria Chiara Rapisarda and Alessio Platania drafted the article and revised it for critically important intellectual content; Salvatore Giovanni Vitale gave the final approval of the version to be published.

\section{References}

1. Huffman LB et al (2016) Maintaining sexual health throughout gynecologic cancer survivorship: A comprehensive review and clinical guide Gynecol Oncol 140(2) 359-68

2. Carter $\mathrm{J}$ et al (2013) The physical consequences of gynecologic cancer surgery and their impact on sexual, emotional, and quality of life issues $J$ Sex Med 10 (Suppl 1) 21-34

3. Santoro G et al (2017) Historical, morphological and clinical overview of placental site trophoblastic tumors: from bench to bedside Arch Gynecol Obstet 295(1) 173-87

4. Jeppesen MM et al (2015) Needs and priorities of women with endometrial and cervical cancer J Psychosom Obstet Gynaecol 36(3) 122-32

5. Rossetti D et al (2014) Efficacy of IVF following conservative management of endometrial cancer Gynecol Endocrinol 30(4) 280-1

6. Vitale SG et al (2016) Surgical treatment of high stage endometrial cancer: current perspectives Updates Surg 68(2) 149-54

7. Rossetti $D$ et al (2016) Concomitant chemoradiation treatment in selected stage I endometrioid endometrial cancers Eur J Gynaecol Oncol 37(5) 657-61 
8. Bellia A et al (2016) Feasibility and surgical outcomes of conventional and robot-assisted laparoscopy for early-stage ovarian cancer: a retrospective, multicenter analysis Arch Gynecol Obstet 294(3) 615-22

9. Rossetti $D$ et al (2016) Laparoendoscopic single-site surgery for the assessment of peritoneal carcinomatosis resectability in patients with advanced ovarian cancer Eur J Gynaecol Oncol 37(5) 671-3

10. Vitale SG et al (2013) The role of cytoreductive surgery in advanced-stage ovarian cancer: a systematic review Updates Surg 65(4) 265-70

11. Laganà AS et al (2015) Cytogenetic analysis of epithelial ovarian cancer's stem cells: an overview on new diagnostic and therapeutic perspectives Eur J Gynaecol Oncol 36(5) 495-505

12. Laganà AS et al (2016) Epithelial ovarian cancer inherent resistance: May the pleiotropic interaction between reduced immunosurveillance and drug-resistant cells play a key role? Gynecol Oncol Rep 18 57-8

13. Kokka $\mathrm{F}$ et al (2015) Hysterectomy with radiotherapy or chemotherapy or both for women with locally advanced cervical cancer Cochrane Database Syst Rev (4) CD010260

14. Vitale SG et al (2015) Recent trends in surgical and reconstructive management of vulvar cancer: review of literature Updates Surg 67(4) 367-71

15. Iżycki D, Woźniak K and lżycka N (2016) Consequences of gynecological cancer in patients and their partners from the sexual and psychological perspective Prz Menopauzalny 15(2) 112-6

16. Vitale SG et al (2016) Comment on: "The consequences of gynaecological cancer in patients and their partners from the sexual and psychological perspective". Prz Menopauzalny 15(3) 186-7

17. Mielcarek P, Nowicka-Sauer K and Kozaka J (2016) Anxiety and depression in patients with advanced ovarian cancer: a prospective study J Psychosom Obstet Gynaecol 37(2) 57-67

18. Vitale SG et al (2016) Comment on: "Anxiety and depression in patients with advanced ovarian cancer: a prospective study" J Psychosom Obstet Gynaecol 18 1-2 DOI: 10.1080/0167482X.2016.1244182

19. Laganà AS et al (2016) Comment on: "Needs and priorities of women with endometrial and cervical cancer" J Psychosom Obstet Gynaecol 18 1-2 DOI: 10.1080/0167482X.2016.1244186

20. Vitale SG et al (2016) Psychology of infertility and assisted reproductive treatment: the Italian situation $J$ Psychosom Obstet Gynaecol 18 1-3 DOI: 10.1080/0167482X.2016.1244184

21. Angarita AM, Johnson CA, Fader AN and Christianson MS (2016) Fertility preservation: a key survivorship issue for young women with cancer Front Oncol 6102

22. Rosen A, Rodriguez-Wallberg KA and Rosenzweig L (2009) Psychosocial distress in young cancer survivors Semin Oncol Nurs 25(4) 268-77

23. Bodurka-Bevers D et al (2000) Depression, anxiety, and quality of life in patients with epithelial ovarian cancer Gynecol Oncol 78 (3 Pt 1) 302-8

24. Tschudin S and Bitzer J (2009) Psychological aspects of fertility preservation in men and women affected by cancer and other life-threatening diseases Hum Reprod Update 15(5) 587-97

25. Canavarro MC and Pires RSA (2011) The impact of gynecological cancer on reproductive issues and pregnancy: psychological implications Curr Womens Health Rev 7 367-78

26. Schover LR (1999) Psychosocial aspects of infertility and decisions about reproduction in young cancer survivors: a review Med Pediatr Oncol 33(1) 53-9 
27. Abu-Rustum NR et al (2006) Fertility-sparing radical abdominal trachelectomy for cervical carcinoma: technique and review of the literature Gynecol Oncol 103(3) 807-13

28. Willows K, Lennox $\mathrm{G}$ and Covens $\mathrm{A}$ (2016) Fertility-sparing management in cervical cancer: balancing oncologic outcomes with reproductive success Gynecol Oncol Res Pract 39

29. Falcone $\mathrm{F}$ et al (2017) Fertility preserving treatment with hysteroscopic resection followed by progestin therapy in young women with early endometrial cancer $J$ Gynecol Oncol 28(1) e2

30. Bentivegna $\mathrm{E}$ et al (2016) Fertility-sparing surgery in epithelial ovarian cancer: a systematic review of oncological issues Ann Oncol 27(11) 1994-2004

31. Chan JL and Wang ET (2016) Oncofertility for women with gynecologic malignancies Gynecol Oncol DOI: 10.1016/j. ygyno.2016.12.013

32. Maltaris T et al (2006) Reproduction beyond cancer: a message of hope for young women Gynecol Oncol 103(3) 1109-21

33. Maltaris T et al (2007) The effect of cancer treatment on female fertility and strategies for preserving fertility Eur J Obstet Gynecol Reprod Biol 130(2) 148-55

34. Quinn GP et al (2007) Discussion of fertility preservation with newly diagnosed patients: oncologists' views $J$ Cancer Surviv 1(2) $146-55$

35. Quinn GP et al (2008) Patient-physician communication barriers regarding fertility preservation among newly diagnosed cancer patients Soc Sci Med 66(3) 784-9

36. Gorini A and Pravettoni G (2011) An overview on cognitive aspects implicated in medical decisions Eur J Intern Med 22(6) 547-53

37. Peate $\mathrm{M}$ et al (2012) Making hard choices easier: a prospective, multicentre study to assess the efficacy of a fertility-related decision aid in young women with early-stage breast cancer Br J Cancer 106(6) 1053-61

38. Pravettoni G and Gorini A (2011) A P5 cancer medicine approach: why personalized medicine cannot ignore psychology J Eval Clin Pract 17(4) 594-6

39. Letourneau JM et al (2012) Pretreatment fertility counseling and fertility preservation improve quality of life in reproductive age women with cancer Cancer 118(6) 1710-7

40. Reh AE et al (2011) Treatment outcomes and quality-of-life assessment in a university-based fertility preservation program: results of a registry of female cancer patients at 2 years $J$ Assist Reprod Genet 28(7) 635-41

41. Baysal Ö et al (2015) Decision-making in female fertility preservation is balancing the expected burden of fertility preservation treatment and the wish to conceive Hum Reprod 30(7) 1625-34

42. Lawson AK et al (2015) Psychological counseling of female fertility preservation patients J Psychosoc Oncol 33(4) 333-53

43. Bastings $L$ et al (2014) Deciding about fertility preservation after specialist counselling Hum Reprod 29(8) 1721-9 